\title{
成人の漢字単語書取における単語属性効果および誤反応特徵
}

\author{
明石 法子1) 三盃 亜美1) 宇野 彰1) \\ 河原 純一郎 ${ }^{2)} \quad$ Max Coltheart ${ }^{3)}$
}

\begin{abstract}
要 約: 書取の認知過程を明らかにするため, 健常成人 48 名に漢字単語の書取課題を実施し, 単語属性効果抢よび誤反応特徵について検討した。正答率掞よび潜時に頻度効果と心像性効果 が見られ，健常成人が語音から綴りを想起する過程には単語の音，意味，緅りに関する語彙情 報を用いて緅りを想起する語彙経路を活用していることが示唆された。 また，書きの一貫性も 正答率抢よび潜時に影響を及ぼしていたことから，音から文字へ直接変換する非語彙経路の活 用も示唆された。書き始めから書き終わりまでの所要時間には画数が強い影響を示したほか, 頻度の影響もわずかに見られた。誤反応分析の結果，主な誤りは，1 字のみ正答，同音異字へ の誤り，および無回答であった。同音異字への誤りは，書きの一貫性が低い語に対する非語彙 経路の活性を反映していると考えられる.
\end{abstract}

索引用語：漢字書取, 単語属性効果, 誤反応特徵, 語裹経路, 非語彙経路

\section{Word Attribute Effects on and Error Analysis of Spelling of Kanji Words in Normal Japanese Adults}

Noriko Akashi ${ }^{1}$, Ami Sambai ${ }^{11}$, Akira Uno ${ }^{1)}$, Junichiro Kawahara ${ }^{2)}$ and Max Coltheart²)

\begin{abstract}
We investigated word attribute effects on and characteristics of errors in spelling to dictation of two-character Japanese Kanji words in 48 Japanese normal adults. Frequency, imageability, and spelling consistency significantly affected spelling accuracy and latency. The frequency and imageability effects are taken to reflect lexical processing, and the spelling consistency effect is taken to reflect sub-lexical processing. These results suggest that both lexical and sub-lexical processing occur during spelling to dictation of Kanji words. Spelling duration was affected by frequency and number of strokes. The spelling errors were mainly classified into three types: one-character correct responses, phonologically plausible errors, and non-responses. This outcome suggests that phonologically plausible errors result from sub-lexical processing for spelling inconsistent words.
\end{abstract}

筑波大学大学院人間総合科学研究科 ${ }^{1)}:$ † 305-8577 茨城県つくば市天王台 1-1-1

中京大学大学院心理学研究科 ${ }^{2)}$ : ₹466-8666 名古屋市昭和区八事本町 101-2

Department of Cognitive Science, Macquarie University ${ }^{3)}$ : Department of Cognitive Science, the Australian Hearing Hub, 16 University Avenue, Macquarie University NSW 2109, Australia

${ }^{1)}$ Graduate School of Comprehensive Human Sciences, University of Tsukuba: 1-1-1, Tennodai, Tsukuba, Ibaraki 305-8577, Japan ${ }^{2}$ Department of Psychology, Chukyo University: 101-2, Yagotohommachi, Showa, Nagoya, Aichi 466-8666, Japan

${ }^{3}$ Department of Cognitive Science, Macquarie University: Department of Cognitive Science, the Australian Hearing Hub, 16 University Avenue, Macquarie University NSW 2109, Australia 2013 年 9 月 26 日受稿 2014 年 1 月 14 日受理 
Key words: writing to dictation of Japanese Kanji words, word attribute effects, characteristics of errors, lexical processing, sub-lexical processing

\section{はじめに}

単語の出現頻度，単語から喚起されるイメージの思 い浮かべやすさを表す心像性，書記素から音素への変 換における対応関係を表す読みの一貫性といった単語 の属性が，音読成績に影響を及ぼすことが知られてい る1,2)。一方，単語属性が書字に及ぼす影響について は十分に検討されていない.

アルファベット言語圈の先行研究では, 聴覚提示さ れた語音に対応する文字列を書くという，書取の認知 過程に影響を及ぼす単語属性に関しては，単語出現頻 度や書きの一貫性のみが検討されている3 ${ }^{3,4}$ ，書きの 一貫性とは, 読みの一貫性が書記素から音素への変換 における一貫性を指すのに対して，音素から書記素へ の変換における一貫性を指し，読みの一貫性と書きの 一貫性は必ずしも一致しない，たとえば“bat”は読 みの場合も書きの場合も一貫語であるが, "green”は 読みの場合は一貫語であり，書きの場合は非一貫語で ある，書記素から音素への変換は一貫しているが，音 素から書記素への変換は一貫しておらず, "grean" や”grene”のような発音上は正しい書き誤りを生じ させる可能性があるからである4)。アルファベット言 語圈の先行研究においては, 頻度扮よび書きの一貫性 が書取潜時に影響すると報告されている

一方，日本の漢字単語の書取に影響を及ぼす単語属 性に関しては，書きの一貫性に関する報告はなく，頻 度や心像性，画数について検討がなされてきた5,6). 成人を対象とした研究においては，書取潜時には低頻 度語においてのみ画数が影響すると報告されてい $る^{5)}$ 。また，典型発達児と読み書きに特異的な困難を もつ発達性読み書き障害児を対象とした研究におい て，発達性読み書き障害児にのみ，書取の正答率に心 像性すなわちイメージの思い浮かべやすさと，画数の 影響が見られたと報告されている ${ }^{6)}$ 。これらの研究か ら, 漢字単語の書取には，単語に対するなじみの程度 や画数，心像性といった属性が影響することが示唆さ れる。また，両研究に打いて同音異字への誤り〔例： /にんめい/(任命) $\rightarrow$ 『任名』つが多く見られており， アルファベット系言語圈での先行研究 ${ }^{3,4)}$ と同様に, 漢字書取においても音から文字への変換における対応 関係，すなわち書きの一貫性が影響していると考えら れる。しかし，これらすべての属性を実験的に統制し
た研究はまだ行われていない．

そこで本研究では, 健常成人に漢字単語の書取課題 を実施し，頻度，心像性，画数，書きの一貫性といっ た単語属性が漢字単語の書取に及ぼす影響の検討およ び誤反応分析を行うことで，書取の認知過程解明への 手掛かりを得ることを目的とする。

\section{方法}

\section{1. 参加者}

首都圈の国立大学 1 校扮よび私立大学 2 校の学生 48 名が実験に参加した。内訳は男性 13 名，女性 35 名で, 平均年齢は 21.8 歳（SD 2.9）であった.

\section{2. 書取課題}

1 ) 刺激

漢字 2 字からなる実在語 144 語を音声合成ソフトに よって音声化し，刺激とした，刺激語は，NTTデー タベース「日本語の語彙特性」に収録されている值を 参考に，頻度，心像性，書きの一貫性，画数の内， 1 つの属性を高低に分類した際，他の属性が統制される よう選定した（表 1)。各属性高群低群に分類された 刺激の例を補遺に示した。すべて音声・文字呈示親密 度 4 以上，すなわち中程度以上のなじみのある単語で あり，小学校 1 年生から 6 年生で習う漢字で構成され ている。モモラ数は 3 もしくは 4 で, 同音異義語をも つ単語は含まれていない。

書きの一貫性に関しては, 先行研究7による読みの 一貫性值の算出方法を参考に, Spelling Friends/ (Spelling Friends + Spelling Enemies) という式で算 出した。算出に用いたコーパスは，NTTデータベー 久「日本語の語彙特性」に収録されている，小学校 1 年生から 6 年生で習う漢字で構成された，親密度 4 以 上の漢字 2 字熟語 5419 語とした，例として，「設問」 という語の書きの一貫性值を算出する。2 字熟語の 1 文字目として，/せつ/という言語音に設という字が対 応する Spelling Friends は設問, 設備, 設立, 設営と, コーパス内に 4 語ある。/せつ/という言語音に他の文 字が対応する Spelling Enemies は切断，接続，節約， 説明などコーパス内に 19 語ある. Spelling Friends を Spelling Friends と Spelling Enemies の合計数で割っ た值 $4 /(19+4) \doteqdot 0.17$ が，「設問」の 1 文字目「設」 の書きの一貫性值となる，2文字目の「問」の書きの 一貫性值も同様に求め,「設問」の書きの一貫性值は, 
表 1 刺激の単語属性值

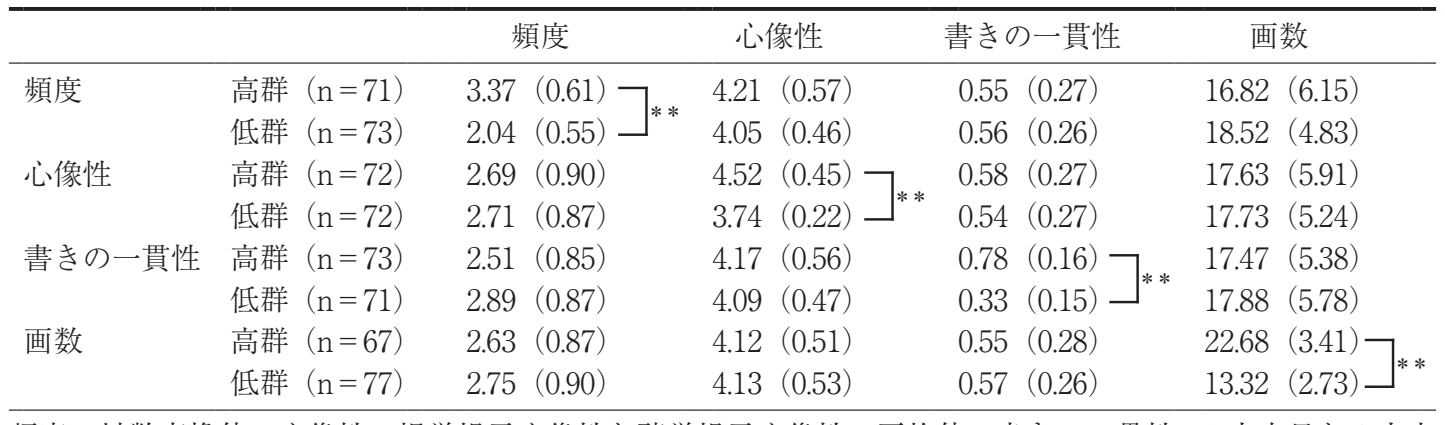

頻度：対数変換值, 心像性：視覚提示心像性と聴覚提示心像性の平均值, 書きの一貫性 : 1 文字目と 2 文字 目の平均值, 画数 : 1 文字目と 2 文字目の総数, $\mathrm{n}$ : 刺激の個数, 数值 : NTT データベース「日本語の語彙 特性」より各刺激の単語属性值を求め, 各属性の高群低群における平均值を算出した。

( ) 内の数值 : 標準偏差, $* *: \mathrm{p}<.01$

1 文字目「設」と 2 文字目「問」の一貫性值の平均值 とした。

\section{2）手続き}

ヘッドフォンから聴こえた音声を漢字 2 字で，でき るだけ速く正確にペンタブレット上の用紙に書き，わ からない場合には×を書くよう教示した．音声提示終 了から書き始めまでの潜時，および書き始めから書き 終わりまでの所要時間をコンピュータ上で測定した。 Matlab 2007 を用いて作成したプログラムにより，刺 激提示後 10 ミリ秒ごとにペンタブレット上のペンの 位置を記録した。

刺激の音圧は参加者ごとに適切なレベルに調節し た。練習 5 試行の後に本試行を実施した。本試行は 48 試行 $\times 4$ セッション実施し，セッションごとに休悡 を挟んだ，本試行の刺激は参加者ごとにランダムな順 序で呈示した。

\section{3 ) 使用器具}

1 枚につき $1.3 \mathrm{~cm}$ 角の枠が 48 試行分 96 個描かれ た縦 $14 \mathrm{~cm} \times$ 横 $22.5 \mathrm{~cm}$ の用紙を、Wacom 社製のぺ ンタブレット上に貼り，セッションごとに用紙を交換 した。

\section{3. 解析方法}

1 ) 単語属性効果の検討

自己修正なく正答した場合の潜時および所要時間に 関して, 試行要因, 参加者要因, 刺激要因をランダム 効果, 頻度 (高, 低), 心像性（高, 低), 書きの一貫 性（高，低）, 画数（高，低）の 4 要因を固定効果と した Mixed Effect Modelingを実施した。平均より 3 $\mathrm{SD}$ 以上長い潜時および所要時間は解析対象から除外 した。正答率に関してはロジスティック回帰分析を 行った.

\section{2 ）誤反応の分類}

書取課題における誤反応を，(1）1 字のみ正答，(2) 同音異字への誤り，（3）無回答，（4）音が類似した語 への誤り, (5) 字画の付加・落, (6) 形態が類似し た字への誤り，(7）意味が類似した字への誤り（8） その他の 8 つのテゴリーに分類した．各カテゴリー の誤反応数を総誤反応数で割り, 各誤反応生起率を算 出した.

\section{結果}

\section{1 . 単語属性効果}

各単語属性の高群と低群における平均正答率, 潜時, 所要時間を図 1 に示した。正答率において頻度, 心像 性，書きの一貫性，画数の主効果が有意であった（頻 度: $z=-10.1, \mathrm{p}<.01, \beta=-0.64, \mathrm{SE}=0.06 ;$ 心像性： $\mathrm{z}=8.38, \mathrm{p}<.01, \quad \beta=-0.51, \mathrm{SE}=0.06$; 書きの一貫性 $\mathrm{z}=-9,67, \mathrm{p}<.01, \quad \beta=-0.60, \mathrm{SE}=0.06$; 画数 $: \mathrm{z}=$ $2.53, \mathrm{p}=<.05, \quad \beta=0.16, \mathrm{SE}=0.06)$ ．潜時において は頻度，心像性，書きの一貫性の主効果が有意であっ た（頻度 $: \mathrm{t}=4.99, \mathrm{p}<.01, \quad \beta=0.12, \mathrm{SE}=0.04$ ；心 像性 : $\mathrm{t}=3.15, \mathrm{p}<.01, \quad \beta=0.12, \mathrm{SE}=0.04$; 書きの 一貫性 $: \mathrm{t}=6.04, \mathrm{p}<.01, \beta=0.24, \mathrm{SE}=0.04)$. 所要 時間に㧍いては画数の主効果が有意であり, 頻度の主 効果が有意傾向であった（画数 $: \mathrm{t}=-14.13, \mathrm{p}<.01$, $\beta=-0.39, \mathrm{SE}=0.03$; 頻度 : $\mathrm{t}=1.73, \mathrm{p}<.10, \quad \beta=$ $0.05, \mathrm{SE}=0.03)$. また, 有意な交互作用は見られなかっ た。

\section{2. 誤反応分析}

各誤反応生起率は，（1）1 字のみ正答 32.8\%〔例：/ みずぎわ/ (水際) $\rightarrow$ 『水』】, (2) 同音異字への誤り〔例: /せつもん/(設問） $\rightarrow$ 『説問』〕29.3\%，（3）無回答 

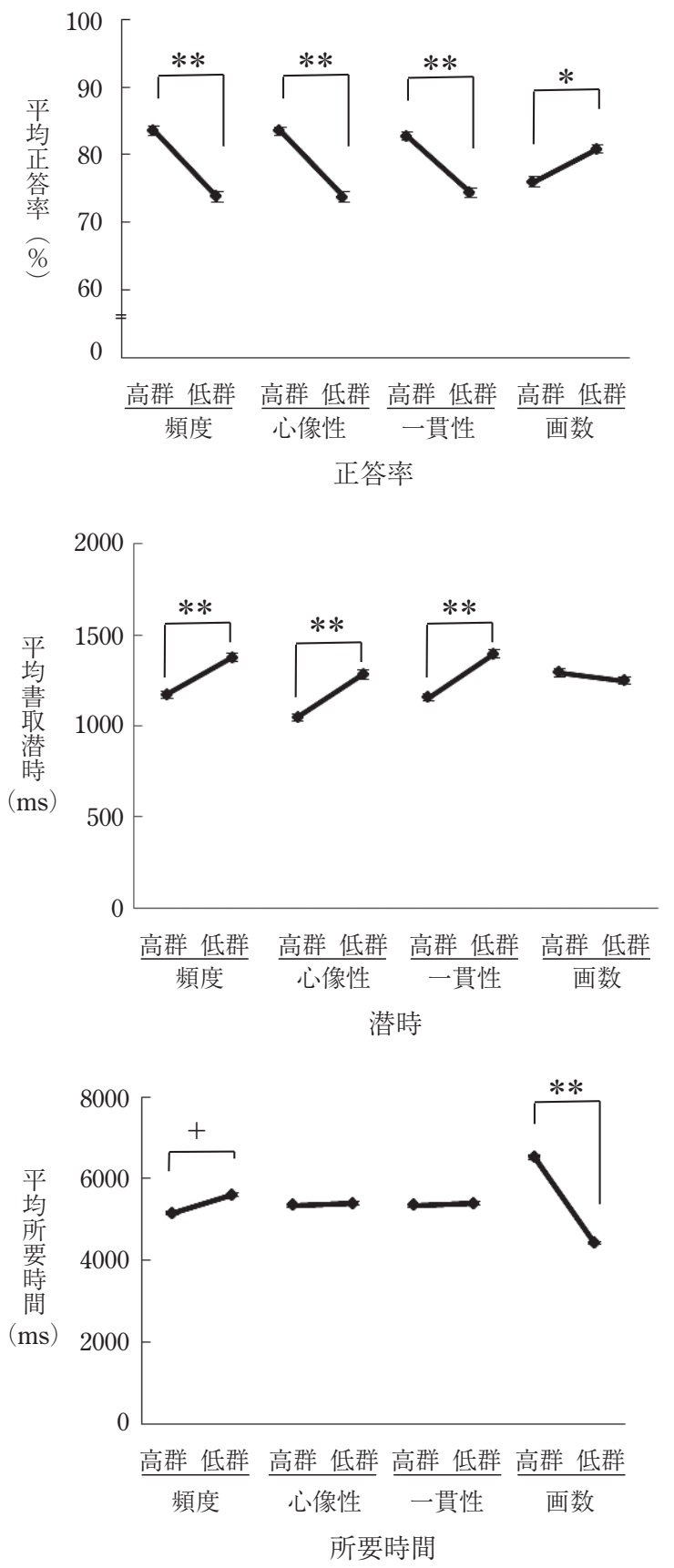

図 1 各単語属性值高群と低群における平均書取正答 率, 潜時, 所要時間。一貫性: 書きの一貫性, **: $\mathrm{p}<.01, *: \mathrm{p}<.05, \quad+\mathrm{p}<.10$, エラーバー : 標 準誤差

22.7\%,(4) 音が類似した語への䛊り〔例:/こぼね/(小 骨） $\rightarrow$ 『小船』 3.6\%,（5）字画の付加・落 3.1\%,（6) 形態が類似した字への誤り〔例：/わたげ/(綿毛) 一『線 毛』1.4\%，（7）意味が類似した字への誤り〔例：/ そくりょう/(測量) $\rightarrow$ 『計量』】 0.01\%,（8）その他 $6.3 \%$ であった。

\section{考察}

\section{1．書取正答率に単語属性が及ぼす影響}

書取正答率に頻度, 心像性, 書きの一貫性, 画数の 影響が見られた。よく目にする単語，イメージが思い 浮かべやすい単語, 音と文字の対応関係が強い単語, 画数が少ない単語は正答率が高いことが明らかになっ た。

\section{2. 書取潜時に単語属性が及ぼす影響}

頻度, 心像性, 書きの一貫性が書取潜時に強い影響 を及ぼした，画数は，先行研究5) と異なり潜時に影響 を及ぼさなかった. 先行研究で見られた画数効果には, 心像性や書きの一貫性など統制されていない要因が影 響していたのではないかと考えられる。あるいは，画 数が多い語群の平均画数と少ない語群の平均画数の差 が, 先行研究では 14.9 画だったのに対し本研究では 9.4 画と小さかったため画数効果が見られなかったという 可能性も考えられる. 少なくとも本研究で刺激に用い た漢字単語に関しては，画数が綴りの想起過程に及ぼ す影響は, 頻度, 心像性，書きの一貫性に比べて小さ かったのではないかと思われた。

アルファベット系言語圈における先行研究3,4) で報 告された書きの一貫性効果が, 本研究においても見ら れた。音と文字の対応の一貫性が高い単語，たとえば 「横笛」のような, /よこ/という音, /ぶえ/という音 に 1 字ずつのみが対応している単語は,「設問」のよ うに/せつ/という音, /もん/という音にさまざまな 文字が対応可能な単語より速く綴りを想起できると考 えられる。この結果から, 成人が漢字単語の緅りを想 起する過程において, 単語の構成音を文字に直接変換 するという，非語彙的な処理を行っていることが示唆 された，同時に，頻度効果㧍よび心像性効果が見られ たことから，単語に関する知識から綴りを想起する語 彙的な処理も行っていることが示唆された。

\section{3．書取所要時間に単語属性が及ぼす影響}

所要時間には, 先行研究 ${ }^{5)}$ と同様, 画数が強い影響 を示したほか，頻度の影響もわずかに見られた，頻度 の高い,すなわちよく目にする漢字単語は, 視覚的表 象 (orthographic representation) が確かであり, 速 く書くことができると考えられる，潜時のみならず所 要時間にも頻度の効果が見られたことから，書字運動 開始後も視覚的表象の活性が持続し, 書字速度に影響 を及ぼすことが示唆された。

\section{4. 誤反応特徵}

本研究の書取課題における主な誤反応は，1字のみ 
正答〔例：/あんまく/(暗幕) $\rightarrow$ 『暗』〕，同音異字へ の誤り〔例：/せつもん/(設問) $\rightarrow$ 『説問』〕，および 無回答であった。成人は単語レベルで正しい綴りが想 起できなかった場合，想起できた 1 字のみを書く，あ るいは語音を分解し同音異字を当てはめるといった方 略をとる傾向があると考えられた。こうした音韻的に もっともらしい誤りは後天的表層失書例に特徵的な誤 りとされている ${ }^{8)}$. 一方, 後天的深層失書例の特徽的 な誤りとされる意味性錯書や視覚性錯書9) はごくわず かしか見られなかった。健常成人の誤反応パターンは 後天的表層失書例と類似しており, 後天的深層失書例 とは異なる可能性が示唆された。

\section{総合考察}

英語の書取におけるシミュレーションモデル4)にお いて, 語音から緅りを想起する過程には, 単語の音, 意味，緅りに関する語彙情報を用いて綴りを想起する 語彙経路，および音素から書記素へ直接変換する非語 彙経路の二重経路が想定されている。本研究において も，書取の正答率および潜時に頻度，心像性，書きの 一貫性効果が見られたことから，語彙経路と非語彙経 路の双方を活用していることが示唆された。誤反応分 析の結果多く見られた同音異字への誤りは，書きの一 貫性が低い語に対し，語彙経路が正しい緅りを出力也 ず，非語彙的な処理のみを行った場合に生じたと考え られる。

謝辞 本研究にご助言くださいましたLD・Dyslexiaセンター 辰巳 格先生，本研究をご支援くださいました公益財団法人博 報児童教育振興会に心から㧍礼申し上げます。

\section{文献}

1) Shibahara N, Zorzi M, Hill M, et al: Semantic effects in word naming: evidence from English and Japanese Kanji.
Q J Exp Psychol, 56A (2): 261-286, 2003.

2) Fushimi T, Ijuin M, Patterson K, et al: Consistency, frequency, and lexicality effects in naming Japanese Kanji. J Exp Psychol, 25 (2): 382-407, 1999.

3) Delattre M, Bonin P and Barry C: Written spelling to dictation: Sound-to-spelling regularity affects both writing latency and durations. J Exp Psychol Learn Mem Cogn, 32 (6): 1330-1340, 2006.

4) Houghton G and Zorzi M: Normal and impaired spelling in connectionist dual-route architecture. Cogn Neuropsychol, 20 (2): 115-162, 2003

5）玉岡賀津雄，高橋 登：漢字二字熟語の書字行動に㧍ける 語彙使用頻度㧍よび書字的複雑性の影響。心理学研究, 70 (1) : 45-50, 1999

6）井村純子，春原則子，宇野 彰，他：発達性読及書き障害 児と小学生の典型発達児における漢字書取の誤反応分析一 小学生の読み書きスクリーニング検査（STRAW）を用い て一. 音声言語医学, $52 ： 165-172,2011$.

7）宇野 彰, 鈴木香菜美，三盃巠美，他：成人領域での認知 神経心理学を発達性 dyslexia 一直接適用する際の問題点 について一表層性と音韻性 dyslexia を中心に一. 音声言 語医学, $50 ： 276-284,2009$

8) Coltheart M, Masterson J and Byng S: Surface dyslexia. Q J Exp Psychol, 35A: 469-495, 1983.

9) Bub D and Kertesz A: Deep agraphia. Brain Lang, 17: 146-165, 1982.

別刷請求先：=305-8577 茨城県つくば市天王台 1-1-1 総合研究 D 棟 520 筑波大学大学院人間総合科学研究科 明石法子

補遺 各単語属性において高群低群に分類された刺激例

\begin{tabular}{lll}
\hline & 高群 & 低群 \\
\hline 頻度 & 切手 & 天女 \\
心像性 & 砂山 & 安直 \\
書きの一貫性 & 論理 & 設問 \\
画数 & 元日 & 謝罪 \\
\hline
\end{tabular}

